\title{
SPORTSMEN COOPETITION: A CASE OF INTERNATIONAL DANCE-SPORT COMPETITION
}

\author{
AUdrius Armas \\ Lithuanian Sports University, Kaunas, Lithuania
}

\begin{abstract}
Sport is considered as a field for the development of social skills of competition, cooperation and collaboration. The assumption is made that latter social skills (and their consistency in form of coopetition) have a higher potential for the development in international context. The scientific problem solved during the research is framed by questions: what is the impact of social skills of competition, cooperation and collaboration on sportsmen coopetition?; and what is the impact of international context on the exertion of latter skills? A case of the International Dance-sport Competition "Ambercouple" is considered as the research environment. The aim of the research is to determine the sportsmen coopetition among dance-sport dancers. The research is provided in stages: 1) the context of international sporting event is presented from the point of its suitability for the research: countries are classified in terms of participating amount, winning amount, differences in competence; 2) interviews with coaches are provided to determine their judgments of coopetition possibilities from international point of view; 3) questionnaire research with participants of the competition is provided; and 4) the model of geographic boundaries of coopetition among dance-sport dancers is composed.
\end{abstract}

Keywords: collaboration; competition; cooperation; coopetition; dancesport; sport event

\section{INTRODUCTION}

Navigating everyday life successfully largely depends on an individual's capacity to engage effectively with the social environment [2]. However, the interests of the individual are often in conflict with the interests of others in 
a social interaction. Jurevičienè et al. [8] emphasize that an important conditions for a harmonious existence in a social group are social skills; moreover, social skills constitute a possibility for an individual to act effectively in a social environment, and lay a foundation for successful socialization.

Deutsch [4] argues that human social interactions are based on their interdependence; the essence of interdependence can manifest in positive as well as in negative form. Johnson and Johnson [7] highlight that the positive manifestation of social interdependence can be envisioned in cooperation, whereas negative - in competition among individuals. Earlier Johnson and Johnson [6] suggested that competitors achieve better results when they cooperate in competition based environment, rather when compete without collaborating. Decety et al. [3] argue that cooperation and competition are two basic modes of social cognition that necessitate monitoring of both one's own and others' actions, as well as adopting a specific mental set; thus, cooperation and competition involve executive functions and mentalizing abilities, both of which play a crucial role during social interactions.

While analyzing scientific literature, a discussion on collaboration can be found [9]. Collaboration encompasses cooperation and coordination. Therefore, the assumption in this paper is that cooperation is possible within a team (couple in dance-sport), whereas collaboration occurs between two or more teams (couples) to reach their specific, as well as mutual goals. The previous research (see [1]) enabled the insight that the nature of social interdependence depends on the level of goals being achieved; three levels of goals can be distinguished: individual goals, group goals, and community (formation of few interrelated groups) goals. Moreover, based on the type of the interaction and the level of goals, individuals tend to engage into a particular form of interrelation: competition, cooperation, or collaboration (the form of interdependence is not restricted - a combination of a few [or even all] forms is possible).

According to Zineldin [14], a situation in which independent parties co-operate with one another and co-ordinate their activities, thereby collaborating to achieve mutual goals, but at the same time compete with each other as well as with others is called coopetition. While analyzing a social structure of coopetition within a multiunit organization, Tsai [12] comes to a finding that coopetition refers to simultaneously cooperative and competitive behaviour. Moreover, a common form of coopetition is knowledge sharing among competitors, and the cooperative aspect of such knowledge sharing refers to the collective use of shared knowledge to pursue common interests.

Considering a case of dance-sport, a clear field for manifestation of social skills of competition, cooperation and collaboration can be envisioned. 
Dance-sport industry is based on human interdependence; moreover, dancers often compete for higher achievements (in a context of individual as well as group-level goal attainment). Being performed in a couple, dancesport dances create a cooperative environment; however, possibility for collaboration with competing couples can be envisioned as well. Making an assumption about the existence of inter-relation between dance-sport and social skill development, the scientific problem solved in this paper is stated by two questions: what is the impact of social skills of competition, cooperation and collaboration on sportsmen coopetition?; and what is the impact of international context on the exertion of latter skills?

A famous sporting event in Lithuania, the International Dance-sport Competition "Ambercouple" was considered as a suitable framework for the research. The event attracts more than thousand spectators and participants from Lithuania and abroad. Accordingly, the aim of the research is to determine the sportsmen coopetition among dance-sport dancers.

The dance-sport has emerged from social dance; its performances are regulated, main moves and figures are canonized. Dance-sport is divided into European Classic (also called Standard or ST): Waltz, Tango, Viennese Waltz, Slow Foxtrot, Quickstep; and Latin American (LA) dance-sport: Samba, Cha Cha, Rumba, Paso Doble, Jive.

Lithuania was the first country in former Soviet Union which joined the ICBD (now the World Dance and Dance-Sport Council). One of the principal competitions of dance-sport in Lithuania "Ambercouple" was first held 50 years ago - in 1964. It is worth noticing that dance-sport competitions with such old traditions are very rarely found. The experience gained during the 50 -years period makes this competition a unique in the region.

According to Idzelevičius [5], dance-sport is the field requiring a precise social analysis and explanation. Thus, the international dance-sport competition is a perfect field for the analysis of sportsmen social skills of coopetition.

\section{MATERIALS AND METHODS}

\section{Subjects}

During the last 14 years, the average amount of couples competing in both groups (ST and LA) in the international category was about 100 (about 50 couples in every group) (Table 1). If assessing the other programs, this amount could be multiplied by five; and if counting every single dancer, every competition accounts for almost 1000 dancers. It can be argued that 
such amounts of participants are not high if compared to huge global competitions; however, in a framework of Lithuania or entire region, "Ambercouple" is one of the most important competitions.

Table 1. The amount of dancers (in couples) and their distribution by countries.

\begin{tabular}{lllll}
\hline & \multicolumn{2}{l}{ Amount of couples } & \multicolumn{2}{c}{ Amount of countries } \\
\cline { 2 - 5 } Year & ST & LA & ST & LA \\
\hline 2014 & 51 & 48 & 12 & 14 \\
\hline 2013 & 62 & 67 & 12 & 17 \\
\hline 2012 & 70 & 79 & 13 & 18 \\
\hline 2011 & 51 & 58 & 10 & 11 \\
\hline 2010 & 58 & 56 & 6 & 9 \\
\hline 2009 & 55 & 61 & 10 & 12 \\
\hline 2008 & 59 & 48 & 8 & 7 \\
\hline 2007 & 48 & 48 & 8 & 9 \\
\hline 2006 & 48 & 41 & 9 & 8 \\
\hline 2005 & 56 & 57 & 7 & 8 \\
\hline 2004 & 41 & 47 & 8 & 9 \\
\hline 2003 & 49 & 52 & 9 & 10 \\
\hline 2002 & 32 & 32 & 11 & 10 \\
\hline 2001 & 44 & 36 & 10 & 11 \\
\hline
\end{tabular}

Note: Source - The World DanceSport Federation [11].

As it can be seen in Table 1, during the last 14 years the popularity of the competition remains steady: the number of participating countries is about 10. Traditionally, the highest amount of participants is from Lithuania: they do not need to travel far, they can go home for a rest, they feel the support from local spectators, etc. Similar advantages attract participants from neighbouring countries (Latvia, Estonia, Russian Federation, Belarus, and Poland); sportsmen from latter countries are frequent participants of "Ambercouple". Their main motivators are: participation in international event, competition with high amount of professionals, gaining international experience. However, the interests of sportsmen from distant countries like Japan, Hong Kong, Israel or Australia can be observed as well.

The results of the analysis of last 14 years of competitions, in terms of participating and winning countries (in the finals, for the first place compete six couples) are provided in Figure 1. 

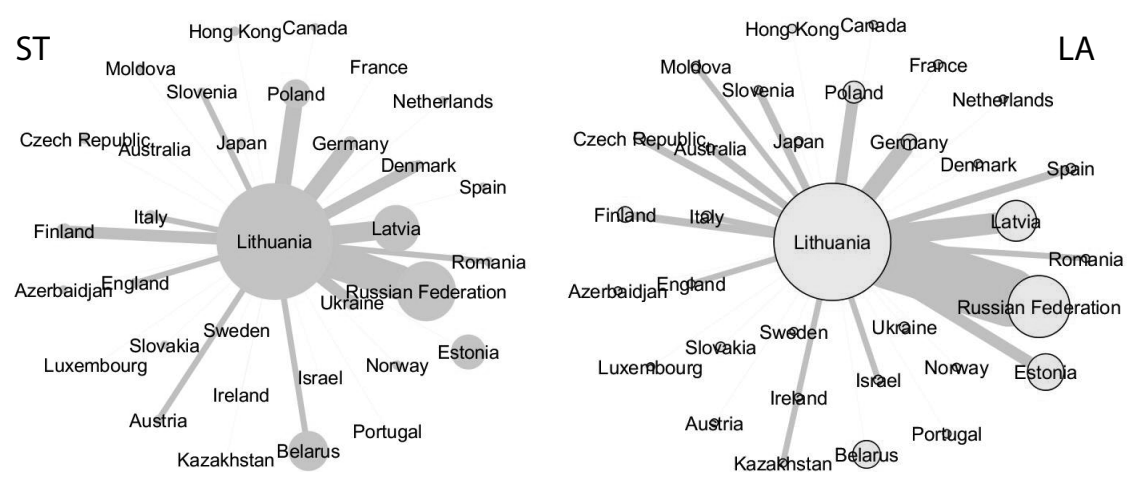

Figure 1. Participating and winning countries, year 2001-2014.

In Figure 1, the international competition in ST group at "Ambercouple" during the years 2001-2014 is provided on the left; the international competition in LA group for the same period is provided on the right. The size of circles represents the amount of participants from different countries (Lithuania as a host country is aligned at the centre). The junctions between the circles represent those countries which sportsmen were chosen to participate in the finals. The thickness of the junctions represents the amount of winners from a particular foreign country.

The retrospective of competition participants in terms of participating and winning countries during the recent 14 years substantiated the fundamental idea of international competition: to provide sportsmen representing different countries with possibility to compete, thus showing their advantages and shortages in international environment. Obviously, international events are very convenient for local athletes for gaining international experience. Consequently, it explains the popularity of "Ambercouple" among Lithuanians and participants from neighbouring countries (Latvia, Belarus, Russian Federation, Poland, and Estonia). However, active Lithuanian athletes' participation in the competition does not guarantee the medal. The analysis of winning countries revealed that winning dancers traditionally divide into two groups. Considering ST, the highest amounts of winners are from Lithuania, Russian Federation and Latvia. This can be explained by the fact that in latter countries exist very strong schools of standard dances. However, strongest world dancers plan and choose competitions in advance; hence, their participation in "Ambercouple" is rare.

On the other hand, in LA group the highest amounts of winners come from Slavic countries: Russian Federation, Poland, and Slovenia, and also Estonia. Thus, the competition gains its international significance by 
attracting those dancers from the region who endeavour showing themselves in international context with best world dancers.

\section{Procedure}

The empiric research in this paper is provided to compose a model of sportsmen coopetition among dance-sport dancers. Based on the scientific analysis, five semi-structural interviews with famous Lithuanian coaches of dance-sport dancers were provided. During the interviews, the theoretical insights about competition, cooperation, collaboration, and coopetition among dance-sport dancers were proved and discussed. Moreover, international context for latter variables was substantiated. The theoretical model of sportsmen coopetition among dance-sport dancers was composed based on scientific as well as practical insights. Four exogenous (independent) and seven endogenous (dependent) latent variables are included in the model and connected by eighteen theoretical causal relations (see Figure 2).

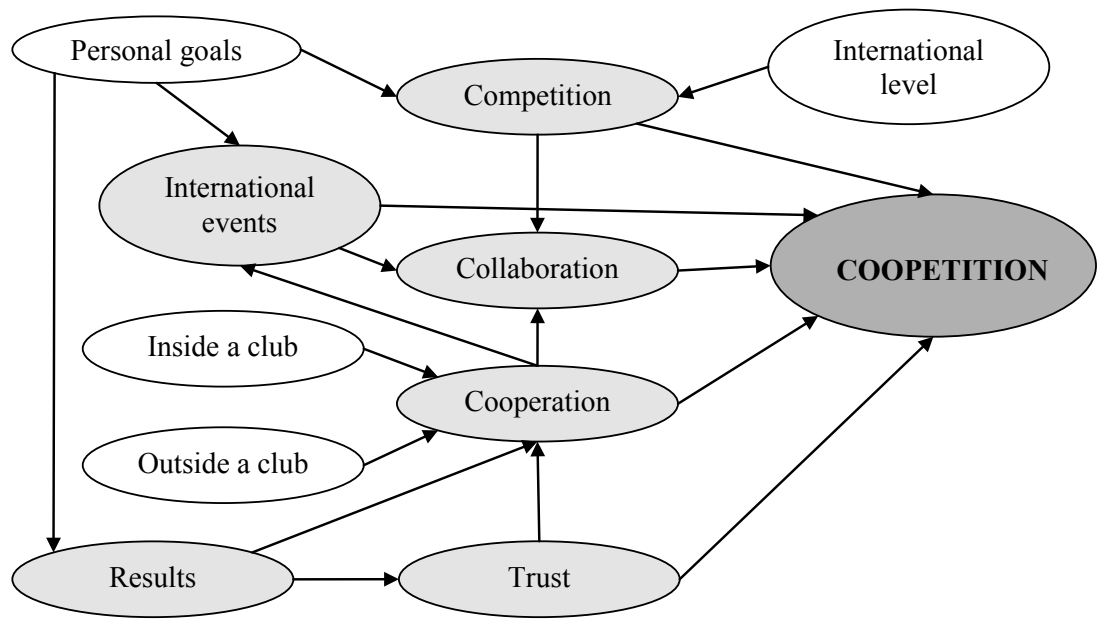

Figure 2. Theoretical model of sportsmen coopetition among DanceSport dancers.

The exogenous latent variables included in the model were chosen to reflect the main reason for coopetition (personal goal achievement), internationality (the striving for international level appreciation), and social interrelation (among club dancers and among dancers outside the club). All the endogenous latent variables (Results, Trust, International Events, Competition, Collaboration, Cooperation, and finally Coopetition) are determined by one or more other variables. The variable 'Trust' was not substantiated theoretically; however, during the interviews, all the coaches 
stressed the existence and the necessity of this variable. It was hypothesized that trust between partners in a couple is achieved based on common results (based mainly on their scores gained in competitions), also, trust leads to better cooperation. Furthermore, the assumption was made that cooperation (between partners in a couple) as well as desire for personal goals' achievement make a positive influence on a decision for participating in international events and their evaluation.

Based on the interviews with coaches, 35 manifest variables were established to reflect the latent variables (from 3 to 6 for each).

Achieving to substantiate the theoretical model of sportsmen coopetition among dance-sport dancers, questionnaire research was provided. 35 statements (manifest variables) were provided for respondent evaluation in 5-point Likert-type scale to assess the extent of their agreement / disagreement. At the end of the questionnaire, 10 questions about respondents' demographic and general dance-sport-related characteristics were provided. The survey was provided on $9^{\text {th }}-11^{\text {th }}$ of May, 2014 (during the event of international dance-sport competition "Ambercouple"). Questionnaires were prepared in three languages: Lithuanian, English, and Russian. Total sample size was 107 respondents representing 6 countries. The sample was composed of 50 men (46.7\%) and 57 women (53.2\%). Respondents' age varied between 18 and 30 years; most respondents belonged to a group of 18-24 years old. Considering the duration of experience in dance-sport, the average respondent indicated 15 years. All the respondents indicated participation in the highest dance-sport class: were dancing the entire program of ST or LA. According to the country represented, respondents distributed as follows: $52 \%$ from Lithuania, $9 \%$ from Belarus, $4 \%$ from Latvia, $18 \%$ from Russian Federation, 11\% from Estonia, and 7\% from Poland. Only three respondents were participating at the competition "Ambercouple" for the first time; ten respondents indicated their second participation; all the others (87.9\%) had participated at the event more than twice.

\section{Statistical analysis}

Structural equation modelling (SEM) using partial least squares (PLS) path modelling methodology using SmartPLS 2.0.M3 software [10] was applied for statistical analysis. 


\section{RESULTS}

After calculating the results provided by respondents, the initial PLS path model was obtained. However, not all manifest variables' outer loadings were obtained high enough. One manifest variable's (reflecting the latent variable 'Personal goals') outer loading was below 0.7 ; hence, this manifest variable was removed from further analysis. Repeated calculations were provided without the latter variable. Assessing the initial PLS Path model, Average Variance Extracted (AVE) values indicated the sufficient degree of convergent validity (all AVE values were obtained higher than 0.5). As Cronbach's alpha tends to provide a severe underestimation of the internal consistency reliability of latent variables in PLS path models [13], a different measure, the composite reliability was applied. The degree of internal consistency reliability was acceptable: all composite reliability values were above 0.7 (see Table 2).

Table 2. Quality Criteria of latent variables.

\begin{tabular}{lccc}
\hline Variable & AVE & Composite Reliability & R Square \\
\hline Coopetition & 0.5817 & 0.8058 & 0.533 \\
\hline Collaboration & 0.6919 & 0.8707 & 0.7362 \\
\hline Competition & 0.6961 & 0.8202 & 0.5388 \\
\hline Cooperation & 0.7373 & 0.8486 & 0.2912 \\
\hline Inside Club & 0.6033 & 0.9006 & 0 \\
\hline International event & 0.5166 & 0.8392 & 0.5662 \\
\hline International level & 0.7582 & 0.8623 & 0 \\
\hline Outside Club & 0.6005 & 0.8177 & 0 \\
\hline Personal Goals & 0.8336 & 0.9092 & 0.2022 \\
\hline Results & 0.5806 & 0.8026 & 0.3779 \\
\hline Trust & 0.5701 & 0.7985 &
\end{tabular}

Note: AVE - Average Variance Extracted

As it can be observed in Table 2, the highest $\mathrm{R}$ Squared value was obtained variable's 'Collaboration' (74\%) and the lowest for variable 'Results' (20\%); accordingly, it can be stated that the amount of variation accounted for in the endogenous constructs is sufficient. Considering the low R Square value for the variable 'Results' it can be argued that many non-social skills (not 
measured by the questionnaire) are needed to excel at competition; thus, $20 \%$ explanation for latter variable is high enough.

As the data was considered as reliable, further calculations of the path coefficients and inner model T-Statistics were provided achieving to substantiate the relations between variables in the theoretical model (see Table 3).

Table 3. Initial model estimation summary.

\begin{tabular}{lccc}
\hline Relation between variables & $\begin{array}{c}\text { Original } \\
\text { Sample (O) }\end{array}$ & $\begin{array}{c}\text { Standard } \\
\text { Error (STERR) }\end{array}$ & $\begin{array}{c}\text { T Statistics } \\
(\mid \text { O/STERR|) }\end{array}$ \\
\hline Collaboration -> Coopetition & 0.2244 & 0.0711 & 3.1564 \\
\hline Competition -> Coopetition & 0.0315 & 0.075 & 0.4199 \\
\hline Competition -> Collaboration & 0.2108 & 0.0391 & 5.3908 \\
\hline Cooperation -> Coopetition & -0.0589 & 0.0441 & 1.3347 \\
\hline Cooperation -> Collaboration & 0.1009 & 0.036 & 2.8037 \\
\hline Cooperation -> International Event & 0.2466 & 0.0385 & 6.4132 \\
\hline Inside Club -> Collaboration & 0.2709 & 0.0584 & 4.6373 \\
\hline International Event -> Coopetition & 0.551 & 0.0678 & 8.1219 \\
\hline International Event -> Collaboration & 0.2798 & 0.0449 & 6.2242 \\
\hline International Event -> Competition & 0.2346 & 0.0531 & 4.416 \\
\hline Outside Club -> Collaboration & 0.1439 & 0.0457 & 3.1464 \\
\hline Personal Goals -> Competition & 0.6236 & 0.0659 & 9.4569 \\
\hline Personal Goals -> International Event & 0.6011 & 0.0593 & 10.1402 \\
\hline Personal Goals -> Results & 0.4495 & 0.0389 & 11.5703 \\
\hline Results -> Cooperation & 0.2444 & 0.065 & 3.7603 \\
\hline Results -> Trust & 0.615 & 0.0402 & 15.2924 \\
\hline Trust -> Coopetition & 0.0022 & 0.0503 & 0.0435 \\
\hline Trust -> Cooperation & 0.3521 & 0.0568 & 6.1993 \\
\hline & & & \\
\hline
\end{tabular}

As it can be observed in Table 3, three relations between variables were found to be non-significant: Competition, Cooperation and Trust had no direct significant effect on Coopetition. Accordingly, latter relations had to be removed from the model.

After removing the non-significant relations form the model, recalculation was performed (see Table 4). 
Table 4. Final model estimation summary.

\begin{tabular}{lccc}
\hline Relation between variables & $\begin{array}{c}\text { Original } \\
\text { Sample (O) }\end{array}$ & $\begin{array}{c}\text { Standard } \\
\text { Error (STERR) }\end{array}$ & $\begin{array}{c}\text { T Statistics } \\
(\mid \text { O/STERR|) }\end{array}$ \\
\hline Collaboration -> Coopetition & $0.2152^{* *}$ & 0.0571 & 3.7685 \\
\hline Competition -> Collaboration & $0.2252^{* *}$ & 0.0398 & 5.6578 \\
\hline Cooperation -> Collaboration & $0.0969^{*}$ & 0.0384 & 2.5220 \\
\hline Cooperation -> International Event & $0.2456^{* *}$ & 0.0394 & 6.2272 \\
\hline Inside Club -> Collaboration & $0.2709^{* *}$ & 0.0598 & 4.5303 \\
\hline International Event -> Coopetition & $0.5505^{* *}$ & 0.0592 & 9.2978 \\
\hline International Event -> Collaboration & $0.2721^{* *}$ & 0.0443 & 6.1494 \\
\hline International Event -> Competition & $0.2286^{* *}$ & 0.0550 & 4.1533 \\
\hline Outside Club -> Collaboration & $0.1418^{* *}$ & 0.0444 & 3.1929 \\
\hline Personal Goals -> Competition & $0.6322^{* *}$ & 0.0678 & 9.3212 \\
\hline Personal Goals -> International Event & $0.6020^{* *}$ & 0.0637 & 9.4464 \\
\hline Personal Goals -> Results & $0.4497^{* *}$ & 0.0398 & 11.2912 \\
\hline Results -> Cooperation & $0.2442^{* *}$ & 0.0626 & 3.9013 \\
\hline Results -> Trust & $0.6148^{* *}$ & 0.0410 & 15.0026 \\
\hline Trust -> Cooperation & $0.3540^{* *}$ & 0.0579 & 6.1164 \\
\hline
\end{tabular}

Note: ${ }^{*} \mathrm{p}<0.05 ;{ }^{* *} \mathrm{p}<0.01$

As it can be seen in Table 4, only one relationship in the model (Cooperation's influence on Collaboration) was found to be statistically significant. Moreover, all the total effects in the final model were found to be statistically significant.

\section{DISCUSSION}

Sportsmen participation in international competitions provides them with experiences, opportunities to show themselves for a wide range of spectators, gain cognition of foreign countries and cultures. The main dancers' motivators for participating in international competition "Ambercouple" were found to be: participation in international event, competition with high amount of professionals, gaining international experience. However, traditionally, the highest amount of foreign participants of the most famous 
international dance-sport competition in Lithuania "Ambercouple" comes from neighbouring countries: Latvia, Estonia, Russian Federation, Belarus, and Poland. Also, international events are very convenient for local dancers for gaining international experience. The competition gains its international significance by attracting those dancers from the region who endeavour showing themselves in international context with best world dancers. Thus, the international dance-sport competition can be a perfect field for the analysis of sportsmen social skills which constitute a possibility for an individual to act effectively in a social environment, and lay a foundation for successful socialization.

The analysis of the research results enabled the creation of general model of sportsmen coopetition among dance-sport dancers (Figure 3). The latent variables' index values are calculated and included into the model. The values are in the range of 84 to 95 scores (on a scale from 0 to 100). As it can be seen in Figure 3, internationality (in terms of participation in international events and competing in international level) as well as cooperation has greatest values of 95 . However, coopetition is relatively lower. The assumption can be made that cooperation and achievements in international context are better motives for sportsmen achievements than social interactions in terms of demonstration of social skills of collaboration and competition.

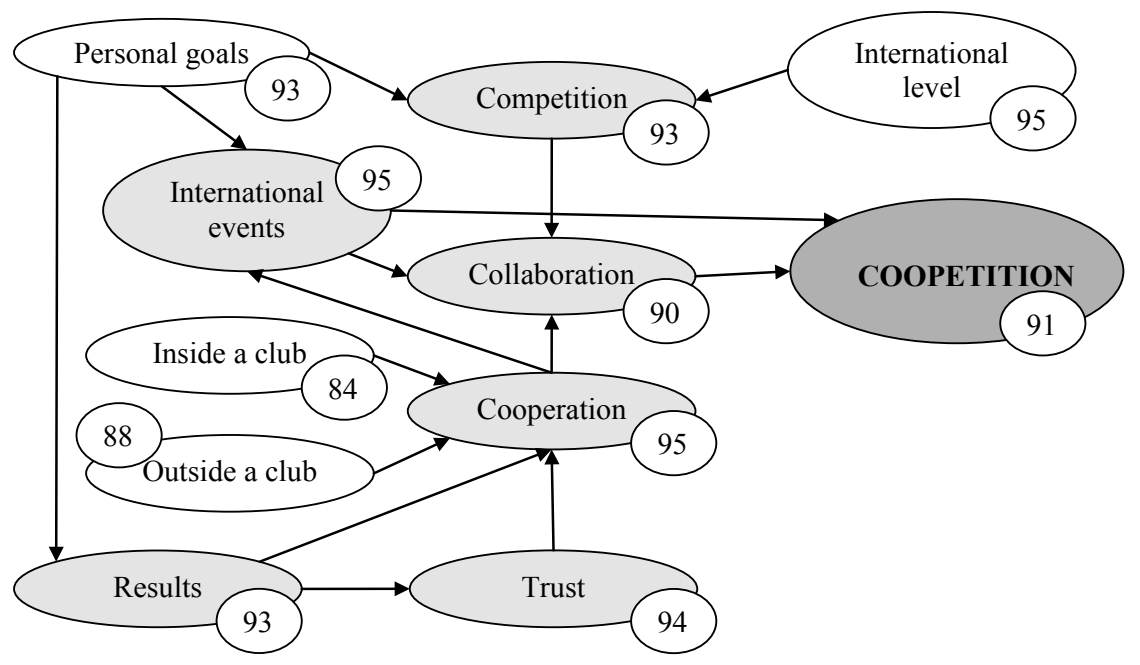

Figure 3. The model of sportsmen coopetition among DanceSport dancers.

Research results denied the existence of direct causal relationships between competition and coopetition, and between cooperation and coopetition. However, both variables (competition and cooperation) in line with 
International Event have explained even $74 \%$ of collaboration, which has a direct effect on coopetition. Moreover, international environment (in a framework of International Event) directly positively influences sportsmen coopetition.

Research results revealed that competition and cooperation can be combined in collaboration, and indirectly affect coopetition through it. Moreover, the international environment (in a framework of International Event) has a direct positive effect on dance-sport dancers' coopetition. It can be stated that global environment is essential for dancers' social skills' of cooperation, competition and collaboration development and their harmonization in terms of coopetition. Summarising the research, it can be stated that global environment is essential for dance-sport dancers' social skill development. The desire for international level achievements stimulates the competition; personal goals for participation in international events indirectly affect collaboration in a framework of the global sportsmen community.

\section{REFERENCES}

1. Armas A, Šniras Šs. (2013) Interdependence-based model of consistency among competition, cooperation and collaboration. Educ Physical Train Sport, 1(88): 9-17

2. Channon S, Collins R, Swain E, Young M, Fitzpatrick S. (2012) The use of skilled strategies in social interactions by groups high and low in self-reported social skill. J Autism Dev Disord, 42(7): 1425-1434

3. Decety J, Jackson PL, Sommerville JA, Chaminade T, Meltzoff AN. (2004) The neural bases of cooperation and competition: an fMRI investigation. Neuroimage, 23: 744-751

4. Deutsch M. (1949) A theory of cooperation and competition. Hum Relat, 2: 129-152

5. Idzelevičius R. (2010) Sportinių šokių istorija ( $2^{\text {nd }}$ ed.). Klaipeda: Klaipèdos universiteto leidykla

6. Johnson RT, Johnson DW. (1999) Making cooperative learning work. Theory into Practice, 38(2): 67-73

7. Johnson DW, Johnson RT. (2009) An educational psychology success story: social interdependence theory and cooperative learning. Educational Researcher, 38: 365-379

8. Jurevičienè M, Kaffemanienė I, Ruškus L. (2012) Concept and structural somponents of social skills. Educ Physical Train Sport, 3(86): 42-52 
9. Kozar O. (2010) Towards better group work: seeing the difference between cooperation and collaboration. English Teaching Forum, 48(2): 16-23

10. Ringle ChM, Wende S, Will A. (2005) SmartPLS 2. Hamburg: SmartPLS, http://www.smartpls.com

11. The World DanceSport Federation (2014) Internet access: http://www.worlddancesport.org

12. Tsai W. (2002) Social structure of "Coopetition" within a multiunit organization: coordination, competition, and intraorganizational knowledge sharing. Organization Science, 13(2): 179-190

13. Werts CE, Linn RL, Jöreskog KG. (1974) Intraclass reliability estimates: testing structural assumptions. Educ Psychol Meas, 34: 25-33

14. Zineldin M. (2004) Co-opetition: The organisation of the future. Marketing Intelligence \& Planning, 22(6/7): 780-789

\section{Correspondence to:}
Audrius Armas
Lithuanian Sports University
Sporto str.6, Kaunas, Lithuania
E-mail: auarmas@gmail.com 